\title{
Early and follow-up results of butterfly resection of prolapsed posterior leaflet in 76 consecutive patients
}

\author{
Tohru Asai, MD, PhD, ${ }^{a}$ Takeshi Kinoshita, MD, PhD, ${ }^{a}$ Tomoaki Suzuki, MD, PhD, \\ Shoichiro Shiraishi, MD, $\mathrm{PhD},{ }^{\mathrm{b}}$ and Masato Koike, $\mathrm{MD}, \mathrm{PhD}^{\mathrm{b}}$
}

\section{ABSTRACT}

Objective: The present study aims to examine the medium-term results of butterfly resection.

Methods: Of 587 consecutive patients who underwent surgery for mitral regurgitation between January 2002 and August 2012, 162 patients underwent valve reconstruction of a prolapsed posterior leaflet. Quadrangular resection $(\mathrm{n}=50$, Quadrangular group) was primarily used before November 2006 (when we innovated the concept of butterfly resection). After that, we mainly used butterfly resection ( $\mathrm{n}=76$, Butterfly group).

Results: Although there was no sign of systolic anterior motion in the Butterfly group, it occurred in 2 patients in the Quadrangular group. One patient in the Quadrangular group died of stroke at postoperative day 17. The mean followup period was $2.2 \pm 1.6$ years for the Butterfly group and $6.1 \pm 2.5$ years for the Quadrangular group. During those periods, 2 patients died of noncardiac causes in the Butterfly group and 1 patient died of an unknown cause in the Quadrangular group. One patient in the Quadrangular group required a reoperation for recurrent mitral regurgitation arising from a new lesion of the anterior leaflet. One patient in the Butterfly group required a reoperation for partial dehiscence of suture at the posterior leaflet. The 3-year estimated survivals free from overall death and reoperation for recurrent mitral regurgitation in the Butterfly group and the Quadrangular group were $97 \% \pm 2 \%$ versus $96 \% \pm 3 \%$ $(P=.89)$ and $95 \% \pm 3 \%$ versus $96 \% \pm 3 \%(P=.75)$, respectively.

Conclusions: Butterfly resection provides acceptable early and medium-term results. (J Thorac Cardiovasc Surg 2015;149:1296-300)

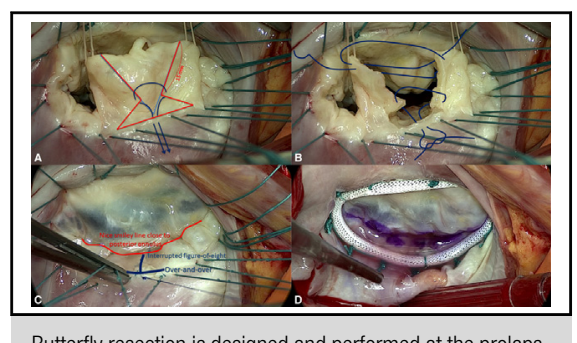

Butterfly resection is designed and performed at the prolapsing posterior leaflet segment.

\section{Central Message}

Butterfly resection of mitral valve repair provides acceptable early and medium-term results for a prolapsed posterior leaflet.

\section{Perspective}

Butterfly resection is a mitral valve repair technique for prolapsing posterior leaflets. Early and mediumterm results of butterfly resection were compared with quadrangular resection. Butterfly group had no SAM but quadrangular group had 2 out of 50. Mortality and valve-related event were not different. Butterfly resection provided comparable early and mediumterm results to quadrangular resection.

See Editorial Commentary page 1301.

See Editorial page 1244
The butterfly resection was introduced as an alternative technique of mitral valve repair for prolapsing posterior leaflets. ${ }^{1}$ Our group has previously described the excellent short-term outcomes of this technique. ${ }^{2}$ One major drawback was the lack of follow-up data to evaluate the durability of this repair technique. The purpose of the present study is to report the medium-term outcomes of patients who have undergone butterfly resection of a

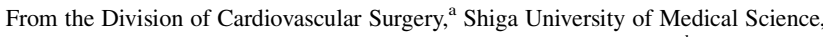
Setatsukinowa, Otsu, Japan; and Division of Cardiovascular Surgery, ${ }^{\mathrm{b}}$ Oumikusatsu Tokusyukai Hospital, Kusatsu, Shiga, Japan.

Received for publication Nov 4, 2014; revisions received Dec 21, 2014; accepted for publication Jan 2, 2015; available ahead of print Jan 31, 2015

Address for reprints: Tohru Asai, MD, PhD, Shiga University of Medical Science, Setatsukinowa, Otsu 520-2192, Japan (E-mail: toruasai@belle.shiga-med.ac.jp). 0022-5223/\$36.00

Copyright (c) 2015 by The American Association for Thoracic Surgery

http://dx.doi.org/10.1016/j.jtcvs.2015.01.001 prolapsed posterior leaflet compared with quadrangular resection.

\section{MATERIALS AND METHODS \\ Patients}

Of 587 consecutive patients who underwent surgery for mitral regurgitation between January 2002 and August 2012 (566 by valve reconstruction and 21 by valve replacement), 162 with isolated posterior leaflet prolapse who underwent mitral valve reconstruction were entered in the study.

Quadrangular resection ( $\mathrm{n}=50$, Quadrangular group), triangular resection $(n=14)$, and chorda replacement $(n=1)$ were primarily used for prolapsed posterior leaflets before November 2006, when we innovated the concept of butterfly resection. After that, we used butterfly resection $(\mathrm{n}=76$, Butterfly group), triangular resection $(\mathrm{n}=19)$, or artificial chorda fixation $(n=2)$. Quadrangular resection was used in 2 patients: 1 with subacute endocarditis and 1 with a short prolapsing segment. Triangular resection or artificial chorda fixation was used mostly for short and narrow prolapsing lesions with no excess tissue throughout the study period. All procedures were performed by the same surgeon (TA). All patients had 


\section{Abbreviation and Acronym}

$\mathrm{SAM}=$ systolic anterior motion

previously granted permission for use of their medical records for research purposes. The study was approved by the institutional review board.

\section{End Points}

The end points were early mortality, valve-related mortality, and major adverse valve-related event. Early mortality was defined as all-cause deaths that occurred with 30 days of surgery. Valve related complications were defined and recorded according to established criteria. ${ }^{3}$

\section{Surgical Technique}

Our typical procedure would be the following, although this sequence may be adjusted considerably according to individual cases and the results of water tests during the procedure. The mitral valve is exposed using a self-retaining retractor (Delacroix Chevalier, Paris, France). Before a water test, each component of the mitral valve is checked, step-by-step: The anterior leaflet, posterior leaflet, chordae tendineae, anterolateral and posteromedial papillary muscles, and left ventricle are examined. At this point, we measure the heights of 4 segments (A2, P1, P2, and P3) of leaflets perpendicularly from the mitral annulus using a small paper scale. A water test confirms the location of any leaflet prolapse. When the prolapsing segment in the posterior leaflet is redundant and high, we use butterfly resection for that redundant prolapsing segment (Figure 1). We start with a simple triangular resection at the free margin, carried out between 2 intact chordae adjacent to the prolapsing segment. By holding a scale next to the leaflet cut margin, we mark the appropriate length (typically $15 \mathrm{~mm}$ for P2) to set the intended height of the resulting leaflet. Then the second resection, a reverse triangular resection, is carried out with its base at the annulus.
The conserved margins of leaflet are then rotated toward the annulus and secured with 5-0 polypropylene. The free corners of the cut leaflet are then brought together and secured, at least temporarily, with another suture in a figure-of- 8 style. The cut edges already approximated to the annulus are then sutured to the annulus, using the free end of the first suture, in an over-and-over fashion. In each step, the water test is repeated to check the leaflet shape and coaptation line. The procedure is completed by mitral annuloplasty with a semi-rigid Carpentier-Edwards Physio II Annuloplasty Ring (Edwards Lifesciences, Irvine, Calif) selected in accordance with the true size of the anterior leaflet.

\section{Antithrombotic Management}

Oral anticoagulation therapy, warfarin sodium, was initiated on postoperative day 1 . The international normalized ratio was targeted at 2.0 to 2.5 . In patients who were in sinus rhythm, anticoagulation therapy was discontinued at 3 months after surgery. In patients with atrial fibrillation, permanent anticoagulation therapy was applied. Oral antiplatelet drug, acetylsalicylic acid, was initiated on postoperative day 1 and continued permanently.

\section{Follow-up}

The patients were assessed at Shiga University of Medical Science 3 months after their initial surgery, and subsequent follow-up data were obtained annually or biennially through direct visits. The clinic visits included a history and physical examination, electrocardiogram, chest radiograph, and transthoracic echocardiogram. The mean follow-up period was $2.2 \pm 1.6$ years (median, 2.0; maximum, 5.5) for the Butterfly group and $6.1 \pm 2.5$ years (median, 6.2; maximum, 10.1) for the Quadrangular group. Clinical and echocardiographic follow-up information was available for $100 \%$ in the Butterfly group and for $94 \%$ in the Quadrangular group. The grade of mitral regurgitation was classified as none, trace, mild, moderate, or severe according to the American College of Cardiology/American Heart Association 2006 guidelines.

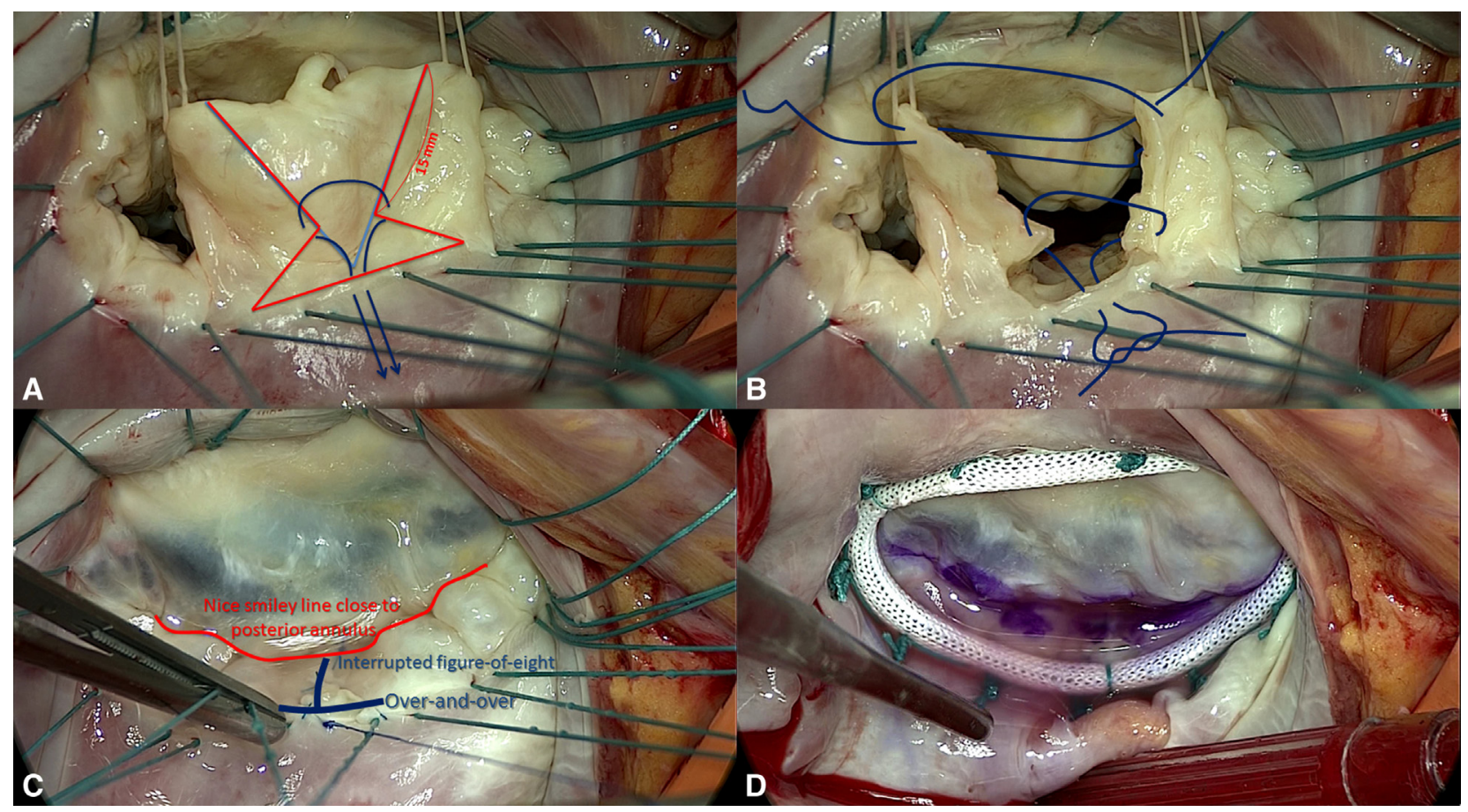

FIGURE 1. Details of butterfly resection: A, Butterfly resection is designed at the posterior leaflet segment, measuring the free edge. B, Conserved margins are being brought to the annulus. C, Symmetric coaptation line is formed close to the posterior annulus. D, After the ring annuloplasty, adequately wide coaptation area is confirmed. 
TABLE 1. Baseline and operative variables

\begin{tabular}{|c|c|c|c|}
\hline & Butterfly & Quadrangular & $P$ value \\
\hline No. of patients & 76 & 50 & \\
\hline Age, y & $58 \pm 14$ & $61 \pm 13$ & .22 \\
\hline Female gender & $19(25)$ & $12(24)$ & .95 \\
\hline Body mass index, $\mathrm{kg} / \mathrm{m}^{2}$ & $23 \pm 3$ & $23 \pm 3$ & .91 \\
\hline Body surface area, $\mathrm{m}^{2}$ & $1.7 \pm 0.2$ & $1.6 \pm 0.2$ & .45 \\
\hline Ejection fraction, $\%$ & $64 \pm 6$ & $67 \pm 6$ & .22 \\
\hline \multicolumn{4}{|l|}{ Dimension, mm } \\
\hline LV end-systolic & $56 \pm 6$ & $56 \pm 6$ & .99 \\
\hline LV end-diastolic & $37 \pm 6$ & $35 \pm 6$ & .33 \\
\hline Left atrial & $44 \pm 8$ & $47 \pm 8$ & .40 \\
\hline \multicolumn{4}{|l|}{ Leaflet pathology } \\
\hline Chordae rupture & $52(68)$ & $37(74)$ & \\
\hline Chordae elongation & $19(25)$ & $10(20)$ & \\
\hline Papillary muscle rupture & $5(7)$ & $3(6)$ & \\
\hline Prolapsed segments & & & .32 \\
\hline $\mathrm{P} 1$ & $14(18)$ & $5(10)$ & \\
\hline $\mathrm{P} 2$ & $41(54)$ & $33(66)$ & \\
\hline $\mathrm{P} 3$ & $21(28)$ & $13(26)$ & \\
\hline \multicolumn{4}{|l|}{ Operative data } \\
\hline Operation time, $\min$ & $228 \pm 47$ & $239 \pm 54$ & .12 \\
\hline Aortic crossclamp time, min & $78 \pm 19$ & $80 \pm 20$ & .67 \\
\hline $\begin{array}{l}\text { Cardiopulmonary bypass } \\
\text { time, } \min \end{array}$ & $108 \pm 22$ & $115 \pm 23$ & .12 \\
\hline Annuloplasty ring size, $\mathrm{mm}$ & $29 \pm 2$ & $28 \pm 2$ & .02 \\
\hline \multicolumn{4}{|l|}{ Concomitant procedures } \\
\hline Tricuspid annuloplasty & $9(12)$ & $5(10)$ & .51 \\
\hline Maze procedure & $21(28)$ & $14(28)$ & .87 \\
\hline $\begin{array}{l}\text { Coronary artery bypass } \\
\text { grafting }\end{array}$ & $6(8)$ & $4(8)$ & .66 \\
\hline Aortic valve replacement & 0 & $1(2)$ & .37 \\
\hline Year of operation & & & .01 \\
\hline $2002-2005$ & 0 & $41(82)$ & \\
\hline 2006-2009 & $32(42)$ & $7(14)$ & \\
\hline 2010-2012 & $44(58)$ & $2(4)$ & \\
\hline
\end{tabular}

Data are number $(\%)$ or mean \pm standard deviation. $L V$, Left ventricular.

\section{Statistical Analysis}

Clinical characteristics were compared between the 2 groups using Pearson's chi-square test for categoric variables, the unpaired $t$ test for normally distributed variables, and the Mann-Whitney $U$ test for skewed variables. The estimated survival and freedom from valve-related events were calculated using the Kaplan-Meier method and compared using the logrank test. All statistical testing was 2-sided. All statistical analyses were performed with the SPSS 20.0 software (SPSS Inc, Chicago, Ill).

\section{RESULTS}

\section{Baseline Characteristics}

Table 1 summarizes the results of a comparison of the 2 groups in baseline and operative variables. No significant difference was found in age, gender, body mass index, body surface area, left ventricular ejection fraction and dimension, left atrial dimension, leaflet pathology, prolapsed segment, leaflet length, and annulus size.

\section{Operative Data}

Most of the operative variables were comparable with the exception of a larger ring size for mitral annuloplasty in the Butterfly group. Although there was no need for a second bypass run and no sign of systolic anterior motion (SAM) in the Butterfly group, SAM occurred in 2 patients in the Quadrangular group. One patient had complete resolution of SAM after inotropic medication was weaned, but the other patient required mitral valve replacement at the same operation. In this case, after we noticed persistent SAM and severe mitral regurgitation even with volume loading and weaning from inotropic agents, a second cardioplegic arrest was introduced and an edge-to-edge suture between A2 and P2 was performed. However moderate-to-severe regurgitation during bypass weaning was still observed. A third cardioplegic arrest was introduced to replace the mitral valve with a mechanical prosthesis.

\section{Leaflet Length}

Of the 162 study patients, leaflet heights at A2, P1, P2, and $\mathrm{P} 3$ segments were directly measured in the 30 consecutive patients between June 2011 and August 2012. The heights of normal versus prolapsed segments were $12.8 \pm$ $3.2 \mathrm{~mm}$ versus $18.6 \pm 4.9 \mathrm{~mm}$ in $\mathrm{P} 1$ segments $(P=.06)$, $16.9 \pm 3.3 \mathrm{~mm}$ versus $22.1 \pm 3.3 \mathrm{~mm}$ in $\mathrm{P} 2$ segments $(P=.01)$, and $13.7 \pm 2.7 \mathrm{~mm}$ versus $17.3 \pm 5.2 \mathrm{~mm}$ in $\mathrm{P} 3$ segments $(P=.06)$, indicating that prolapsed lesions have various degrees of leaflet redundancy compared with normal leaflet. The heights of the prolapsed leaflet repaired by butterfly resection $(\mathrm{n}=19)$ were $21.9 \pm 3.3 \mathrm{~mm}$, by triangular resection $(\mathrm{n}=9)$ were $16.4 \pm 4.2 \mathrm{~mm}$, and by artificial chorda fixation $(\mathrm{n}=2)$ were $12.5 \pm 0.7 \mathrm{~mm}$ $(P=.01$, butterfly vs triangular resection; $P=.02$, triangular resection vs artificial chorda fixation).

\section{Early Results}

The 30-, 60-, and 90-day mortality rates for all patients were $0.8 \%$ (1/126), $0.8 \%$ (1/123), and $0.8 \%$ (1/121), respectively. One patient in the Quadrangular group died of stroke at postoperative day $17(2.0 \%)$. The incidence of stroke within 30 days after surgery was $2.6 \%$ (2/76) in the Butterfly group and $2.0 \%$ (1/50) in the Quadrangular group. No patients required a new permanent pacemaker or defibrillator within 14 days after surgery.

\section{Follow-up Results}

Two late deaths occurred during follow-up in the Butterfly group. Mediastinitis and stroke developed in 1 patient early after surgery, who was managed in an intensive care unit. He subsequently underwent excision of mitral valve vegetation demonstrated by transthoracic echocardiography at postoperative day 17 , but the patient died at postoperative day 111. In intraoperative findings, vegetation was identified only in the anterior leaflet, both the anterior and the posterior leaflets themselves were intact, and recurrent mitral regurgitation was not found. The other patient died 

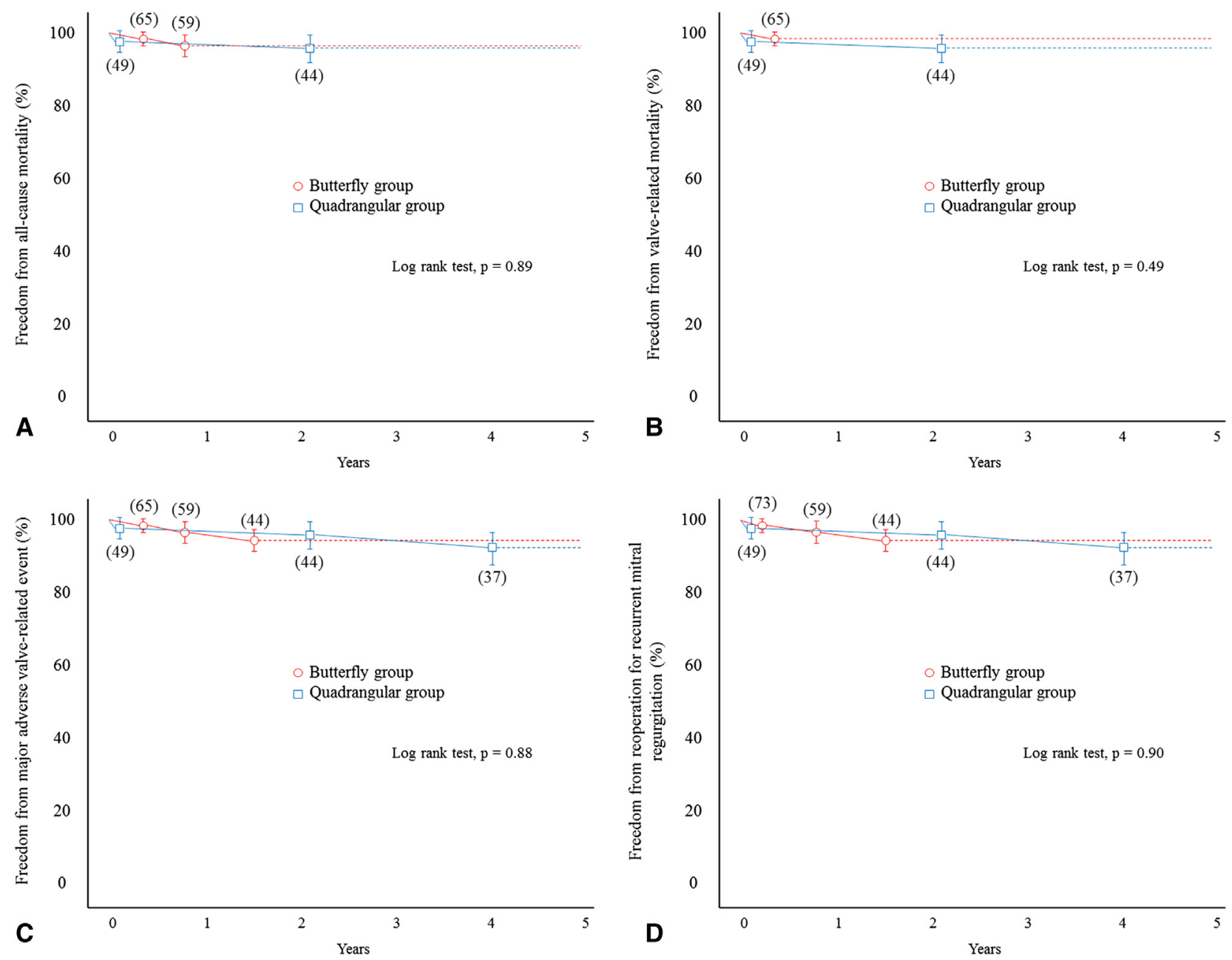

FIGURE 2. Kaplan-Meier curves: freedom from all-cause mortality (A), freedom from valve-related mortality (B), freedom from major adverse valverelated event (C), and freedom from reoperation from recurrent mitral regurgitation (D). Each symbol represents an event, vertical bars are $68 \%$ confidence limits (equivalent to \pm 1 standard error) of Kaplan-Meier estimates, and numbers in parentheses are number of patients at risk and being traced.

of malignancy at postoperative day 273. One patient in the Quadrangular group died of an unknown cause at postoperative day 758 . The 3-year survival and freedom from valverelated mortality in the Butterfly and the Quadrangular group were $96.8 \% \pm 2.2 \%$ versus $95.8 \% \pm 2.9 \%(\log$ rank test, $P=.89)$ and $98.5 \% \pm 1.5 \%$ versus $95.8 \% \pm$ $2.9 \%(P=.49)$, respectively (Figure $2, A$ and $B)$. One patient in the Quadrangular group required a reoperation for recurrent mitral regurgitation arising from a new lesion of the anterior leaflet at postoperative day 3772 . One patient in the Butterfly group required a reoperation for partial dehiscence of suture at the posterior leaflet at postoperative day 615. One patient in the Quadrangular group had a stroke at postoperative day 194. No case of valve thrombosis or bleeding event or additional cases of embolism or endocarditis were observed during follow-up. The 3-year freedom from major adverse valve-related event and reoperation for recurrent mitral regurgitation in the Butterfly and Quadrangular groups was $94.7 \% \pm 3.0 \%$ versus $95.8 \%$ $\pm 2.9 \%(P=.88)$ and $94.8 \% \pm 3.0 \%$ versus $95.8 \% \pm$ $2.9 \%(P=.90)$, respectively (Figure $2, C$ and $D)$.

\section{DISCUSSION}

The main finding of the present study is that butterfly resection provided acceptable medium-term results at least comparable to those by quadrangular resection in patients with posterior leaflet prolapse.

Quadrangular resection $^{5}$ or the sliding leaflet technique ${ }^{6}$ have been the established techniques to repair prolapsed posterior leaflet lesions and have shown excellent long-term outcomes. ${ }^{7,8}$ Butterfly resection has been developed as a simple technique with distinctive advantages. It allows an adjustable height reduction of the new posterior leaflet with minimal tissue resection and requires no annular plication. This technique also offers a potential benefit against SAM typically seen in patients with excessively high posterior leaflets because it can shift the coaptation line of the mitral leaflets away from the ventricular 
septum. ${ }^{2}$ In the present study, no sign of SAM was observed in the Butterfly group throughout the study period, whereas SAM occurred in 2 patients in the Quadrangular group, indicating that the protective effect of butterfly resection against SAM is maintained for several years after surgery.

We select an appropriate repair technique after careful assessment of leaflet configurations and degrees of leaflet redundancy. As shown in the "Results" section, chronic mitral regurgitation through a prolapsed lesion is often associated with leaflet redundancy, and its degree varies considerably among patients. The typical height of normal posterior leaflets has been reported to be $9 \mathrm{~mm}$ in $\mathrm{P} 1,14$ $\mathrm{mm}$ in $\mathrm{P} 2$, and $10 \mathrm{~mm}$ in $\mathrm{P} 3 .{ }^{9}$ After directly measuring the height of mitral leaflet intraoperatively, butterfly resection was generally indicated when the height of the prolapsing segment exceeded $15 \mathrm{~mm}$ and used in $67 \%$ of patients in our series. The design of each butterfly resection was specifically adjusted to produce approximately $15 \mathrm{~mm}$ in P2 and $12 \mathrm{~mm}$ in P1 and P3 in most patients. We avoided using this technique for short prolapsing segments with no excess tissue, such as were occasionally observed with acute rupture of papillary muscles or chordae. In these situations, a height reduction of the prolapsed segment is not necessary.

Posterior leaflet prolapse has been treated by quadrangular resection and ring annuloplasty for many years. Although it is a classic and reproducible method, this technique may predispose to SAM and resultant left ventricular outflow obstruction. The current incidence of SAM after mitral valve repair in patients with degenerative disease remains in the range of $6.1 \%$ to $11.0 \%$ in recent studies. ${ }^{10-13}$ Numerous techniques ${ }^{14-16}$ and medical managements have been proposed to reduce the incidence of SAM after degenerative mitral valve repair. Loulmet and colleagues ${ }^{17}$ reported a decreased incidence of post-repair SAM in the more recent era. However, there is also a tendency to operate on patients in earlier stages with preserved left ventricular function, and this may insidiously increase the risk of SAM in future surgical candidates. ${ }^{12}$ Butterfly mitral repair can be safely performed without increasing the risk of SAM, and we proved that this procedure is feasible in midterm outcomes. We believe that this method of combined height reduction and prolapse elimination, offering advantages over standard quadrangular resection, is a valuable technique to have in every cardiac surgeon's toolbox.

\section{Study Limitations}

First, a completely fair comparison between the 2 groups could not be done because of potential retrospective selection bias in different time periods. Quadrangular resection was used during an early period of our series with consequently longer follow-up, whereas the butterfly resection group had shorter follow-up. Second, the lack of long- term follow-up data did not allow us fully to evaluate the durability of butterfly resection.

\section{CONCLUSIONS}

Butterfly resection can be safely used for the majority of patients with redundant prolapsed posterior leaflet, and it provides acceptable medium-term results.

\section{Conflict of Interest Statement}

Authors have nothing to disclose with regard to commercial support.

\section{References}

1. Asai T, Kinoshita T, Nishimura O, Kambara A, Suzuki T, Matsubayashi K. A novel design of posterior leaflet butterfly resection for mitral valve repair. Innovations (Phila). 2011;6:54-6.

2. Asai T, Kinoshita T, Hosoba S, Takashima N, Kambara A, Suzuki T, et al. Butterfly resection is safe and avoids systolic anterior motion in posterior leaflet prolapse repair. Ann Thorac Surg. 2011;92:2097-102.

3. Akins CW, Miller DC, Turina MI, Kouchoukos NT, Blackstone EH, Grunkemeier GL, et al. Guidelines for reporting mortality and morbidity after cardiac valve interventions. J Thorac Cardiovasc Surg. 2008;135: 732-8.

4. Bonow RO, Carabello BA, Chatterjee K, de Leon AC, Faxon DP, Freed MD, et al. ACC/AHA 2006 guidelines for management of patients with valvular heart disease. Circulation. 2006;114:e84-231.

5. Carpentier A. Cardiac valve surgery-the "French correction." J Thorac Cardiovasc Surg. 1983;86:323-7.

6. Jebara VA, Mihaileanu S, Acar C, Brizard C, Grare P, Latremouille C, et al. Left ventricular outflow tract obstruction after mitral valve repair. Circulation. 1993; 88:II30-4.

7. Perier P, Stumpf J, Götz C, Lakew F, Schneider A, Clausnizer B, et al. Valve repair for mitral regurgitation caused by isolated prolapse of the posterior leaflet. Ann Thorac Surg. 1997;64:445-50.

8. Mohty D, Orszulak TA, Schaff HV, Avierinos JF, Tajik JA, Enriquez-Sarano M. Very long-term survival and durability of mitral valve repair for mitral valve prolapse. Circulation. 2001;104:S1-7.

9. Carpentier A, Adams DH, Filsoufi F. Techniques in type II posterior leaflet prolapse. In: Carpentier A, Adams DH, Filsoufi F, eds. Carpentiers Reconstructive Valve Surgery. Philadelphia: Saunders, Elsevier; 2010:30-3.

10. Brown ML, Abel MD, Click RL, Morford RG, Dearani JA, Sundt TM, et al. Systolic anterior motion after mitral valve repair: is surgical intervention necessary? J Thorac Cardiovasc Surg. 2007;133:136-43.

11. Crescenzi G, Landoni G, Zangrillo A, Guarracino F, Rosica C, La Canna G, et al. Management and decision-making strategy for systolic anterior motion after mitral valve repair. J Thorac Cardiovasc Surg. 2009;137:320-5.

12. Manabe S, Kasegawa H, Fukui T, Tabata M, Shinozaki T, Shimokawa T, et al. Influence of left ventricular function on development of systolic anterior motion after mitral valve repair. J Thorac Cardiovasc Surg. 2012;146:291-5.

13. Varghese R, Anyanwu AC, Itagaki S, Milla F, Castillo J, Adams DH. Management of systolic anterior motion after mitral valve repair: an algorithm. J Thorac Cardiovasc Surg. 2012;143:S2-7.

14. Abicht TO, Andrei AC, Kruse J, McDonald E, Li Z, McCarthy PM. A simple approach to mitral valve repair: posterior leaflet height adjustment using a partial fold of the free edge. J Thorac Cardiovasc Surg. 2014;148: 2780-6.

15. Calafiore AM, Iacò AL, Ibrahim A, Al-Amri H, Refaie R, Own A, et al. A novel and simple technique for correction of posterior leaflet prolapse due to chordal elongation or rupture. J Thorac Cardiovasc Surg. 2014;148:1407-12.

16. Sawazaki M, Tomari S, Izawa N, Ueda Y. Hourglass-shaped resection technique for repair of tall mitral valve posterior leaflet prolapse. J Thorac Cardiovasc Surg. 2013;146:275-7.

17. Loulmet DF, Yaffee DW, Ursomanno PA, Rabinovich AE, Applebaum RM, Galloway AC, et al. Systolic anterior motion of the mitral valve: a 30-year perspective. J Thorac Cardiovasc Surg. 2014;148:2787-94. 